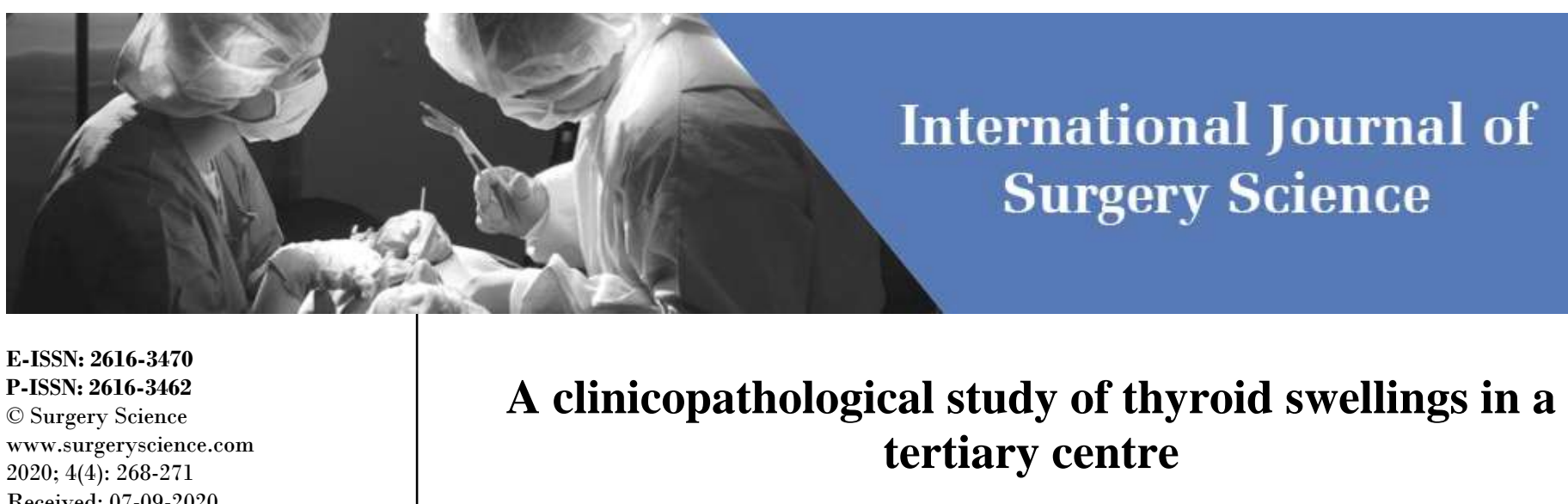

Received: 07-09-2020

Accepted: 11-10-2020

Dr. Ashok Gopinath

Associate Professor, Department of General Surgery, Sree Mookambika Institute of Medical Sciences,

Kulasekharam, Kanyakumari,

Tamil Nadu, India

Aswathy Harikumar

Junior Resident, Department of General Surgery, Sree Mookambika

Institute of Medical Sciences,

Kulasekharam, Kanyakumari,

Tamil Nadu, India

\section{Karthick MP}

Junior Resident, Department of

General Surgery, Sree Mookambika

Institute of Medical Sciences,

Kulasekharam, Kanyakumari,

Tamil Nadu, India

\section{Anandaraj A}

Junior Resident, Department of General Surgery, Sree Mookambika Institute of Medical Sciences,

Kulasekharam, Kanyakumari,

Tamil Nadu, India

\section{Corresponding Author:}

Dr. Ashok Gopinath

Associate Professor, Department of General Surgery, Sree Mookambika Institute of Medical Sciences,

Kulasekharam, Kanyakumari,

Tamil Nadu, India

\section{Dr. Ashok Gopinath, Aswathy Harikumar, Karthick MP and Anandaraj A}

\author{
DOI: https://doi.org/10.33545/surgery.2020.v4.i4e.568
}

\section{Abstract}

Background: Thyroid swelling continues to be prevalent in various parts of India. The swellings are to be clinically detected initially followed by imaging and tissue diagnosis. The main objective of the study was to observe clinical presentations of the thyroid swellings and to correlate the clinical diagnosis with that of pathological diagnosis. To study the spectrum of clinical presentations of thyroid swellings and the accuracy of FNAC in the diagnosis of thyroid swellings

Materials and Methods: Patients with obvious thyroid swellings were included in a prospective study which was conducted for a year in a tertiary centre. Various entities like clinical examination, ultrasonological studies and tissue diagnosis were included.

Results: Out of the 65 patients included in the study, incidence of thyroid swellings was much higher in the age distribution between 30-50 years. On ultrasonographic studies, 18 patients were radiologically diagnosed with carcinoma thyroid and colloid goiter each, constituting $27.7 \%$ of the total. Another 17 cases were diagnosed with multinodular goitre with $26.2 \%, 4$ cases with thyroiditis $(6 \%), 3$ cases with solitary thyroid nodule and hashimotos thyroiditis each $(4.6 \%)$ and 2 cases of colloid cyst $(3.1 \%)$. On comparison of clinical diagnosis with FNAC, of 22 cytologically diagnosed malignant cases, 16 cases were clinically diagnosed. On correlation of the histopathological findings of 65 cases with that of the fine needle aspiration cytology, 60 cases matched the reports with each other, with accuracy rate of $92.30 \%$. Whereas, of the remianing 5 cases, 3 were of follicular adenoma and of 2 cytologically diagnosed colloid cyst showed up to be colloid goitre.

Conclusion: Thyroid swellings are more predominantly seen in female gender in the age group of 30-50 years. Most of the swellings are benign in nature, of which colloid goitre is the most common in our study. Fine needle aspiration cytology (FNAC) is a valuable and cost effective pre-operative investigation for thyroid swellings. Surgical management is the definite treatment for thyroid swellings, of which total thyroidectomy is the most preferable type in our centre.

Keywords: Thyroid gland, thyroid swellings, ultrasonogram, FNAC, histopathological studies

\section{Introduction}

The thyroid gland is an important organ occupying the central compartment of the neck lying in front of the neck ${ }^{[1]}$. Its main function is regulation of the basal metabolic rate, stimulates somatic and psychic growth, and plays an important role in calcium metabolism ${ }^{[2]}$. Enlargement of thyroid gland (Goitre), have been recognised since 2700 b.c., in spite of no documentation about the gland was found until the Renaissance period. Among the endocrine organs, diseases of the thyroid gland are the most common ${ }^{[3]}$. Majority of the thyroid swellings are benign although nearly $5 \%$ are proved to be malignant. Though most patients have a favourable prognosis, approximately 1200 people die of thyroid cancer each year ${ }^{4}$. Normal thyroid gland is impalpable. Enlargement of thyroid gland is the most common manifestation of thyroid disease [5]. There are a number of different diagnostic tests like biochemical tests (thyroid function tests), radiological studies (Ultrasonogram), and histopathological studies (fine needle aspiration cytology) are present for the evaluation of thyroid swellings. Proper knowledge about these tests and their significance helps in early diagnosis and further management of various thyroid diseases. Anti-thyroid drugs along with surgery remain mainstay of management for thyroid swellings.

\section{Materials and Methods}

In this prospective study, a total of 65 patients, who attended the Department of Surgery, Sree Mookambika Institute of Medical Sciences, Kulashekharam with clinically diagnosed thyroid swelling were included. 
All the patients were clinically examined in detail with respect to its duration, size, consistency, mobility, fixity to surrounding structures. Any palpable cervical lymph nodes were checked for following which their thyroid profile and ultrasonogram were performed. Inclusion criteria included patients with clinically detected thyroid swellings and euthyroid patients with normal thyroid function tests. Once the clinical diagnosis was obtained, patients were then subjected for fine needle aspiration cytological examination. They were then explained about the diagnosis and the need for surgery. After obtaining consent and all preoperative investigations such as hematological investigations, X-ray chest and neck, indirect laryngoscopy, pre anesthetic check-up was done and was planned for surgery. All the patients underwent total thyroidectomy following FNAC. All the specimens were fixed in $10 \%$ buffered formalin and sent for histopathological examination and the results were recorded. Statistical analysis was done using SPSS 23.0.

\section{Results}

Out of the 65 patients included in the study, incidence of thyroid swellings was much higher in the age distribution between 30-50 years. About 70.8 percent of total patients belonged to this age group. Among them higher prevalence were noted among the female gender of about $95 \%$ (Graph-1, 2). On detailed clinical examination, each patient was examined based on the size, site, shape and movement of the swelling with deglutition in Pizzillo's method. On palpation, the surface, consistency, mobility of the swelling along with the cervical lymph node status was noted. Of 65 patients, 22 patients with diffuse goitre $(33.8 \%), 19$ patients were diagnosed with multinodular goitre (29.2\%), 16 patients with carcinoma thyroid (24.6\%), 8 patients with solitary nodule (12.3\%) (Table-1).

Various ultrasound features indicative of benign nodule:

- Micro-cystic spaces with thin walls, comprising $>50 \%$ of the nodule

- Purely cystic nodule3 and nodules with a cystic component containing colloid

- Egg shell type calcification around the periphery of a nodule

- Iso-echoic or (mildly) hyper-echoic in relation to the surrounding normal thyroid tissue

- Peripheral vascularity on colour flow or power Doppler

- Features suggestive of malignant nodule :

- A solid hypo-echoic nodule, which may contain hyperechoic foci (i.e. microcalcification)

- An irregular margin, intra nodular vascularity and absence of an associated halo

- A'taller than wide' shape referring to Anterior/Posterior AP diameter > Transverse (TR) diameter

- An irregular or spiculated margin and a 'taller than wide' shape

- Egg shell type calcification around the periphery of a nodule with a broken calcified rim

Following the clinical diagnosis, patients were subjected to ultrasonogram studies in which, of the 65 cases, 18 patients were radiologically diagnosed with carcinoma thyroid and colloid goiter each, constituting $27.7 \%$ of the total. Another 17 cases were diagnosed with multinodular goitre with $26.2 \%, 4$ cases with thyroiditis $(6 \%), 3$ cases with solitary thyroid nodule and hashimotos thyroiditis each $(4.6 \%)$ and 2 cases of colloid cyst (3.1\%) (Graph-3). FNAC is often considered as the gold standard diagnostic test in the evaluation of thyroid swellings. In this study, out of 65 patients, 22 cases were identified to be colloid goitre $(33.8 \%), 12$ cases to be papillary carcinoma $(18.5 \%), 11$ cases to be hashimotos thyroiditis (16.9\%), 10 cases to be follicular neoplasia (15.4\%), 7 cases to be subacute thyroiditis $(10.8 \%)$ and 2 cases to be of colloid cysts $(3.1 \%)$. One case could not be differentiated due to inadequate specimen and had to repeat FNAC later. On comparison of clinical diagnosis with FNAC, of 22 cytologically diagnosed malignant cases, 16 cases were clinically diagnosed. Of 49 cases of diffuse and nodular goitre clinically detected, 22 were cytologically identified to be as colloid goitre, 2 cases to be as colloid cysts, 11 of hashimotos thyroiditis and 7 of subacute thyroiditis and the remaining 6 cases were found out to be malignant (Graph-4). All 65 patients underwent total thyroidectomy and on further histopathological examination, 46 cases were diagnosed to be benign and 19 cases to be malignant. Of the benign cases, 25 cases were colloid goitre, 18 cases of thyroiditis, 3 cases of follicular adenoma of the malignant cases, 12 cases of papillary carcinoma and 7 cases of follicular carcinoma were diagnosed (Graph-5, 6). On correlation of the histopathological findings of 65 cases with that of the fine needle aspiration cytology, 60 cases matched the reports with each other, with accuracy rate of $92.30 \%$. Whereas, of the remianing 5 cases, 3 were of follicular adenoma and of 2 cytologically diagnosed colloid cyst showed up to be colloid goitre (Table-2).

\section{Discussion}

In our study, $70.8 \%$ of patients belonged to the age group between 31-50 years of age. A study done by Halbhavi SN et al., which included 60 patients showed that that the mean age of onset was of 38.6 years of age, with maximum incidence of thyroid swellings in the age group $31-40$ years ${ }^{[7]}$ of the 65 cases, 62 cases were female patients (95.4\%)and only had 3 male patients $(4.6 \%)$ which correlated with the studies conducted by Kusum Borsaikia et al., showing $83.49 \%$ of female cases and $16.5 \%$ of male cases ${ }^{[8]}$ by Ghazaleh et al. ${ }^{[9]}$ (84.0\% female and $16.0 \%$ male) and Md. Shafiqul Islam et al. ${ }^{10}$ where $28.88 \%$ of male cases and $71.12 \%$ of female cases, representing Male:Female ratio of 1:2.46. Most of the patients clinically presented with a swelling in front of the neck, in the region of thyroid. Only patients in euthyroid state were included in the study. With the help of Ultrasonography (USG) the location and type of lesion were clinically studied of which 19 cases were detected to be malignant in nature whereas of the 46 benign cases. FNAC is simple, cost effective, diagnostic test, with excellent patient compliance, often used as the initial screening test for diagnosis of thyroid nodules [11]. The sensitivity and specificity fine needle aspiration cytology ranges from $57.0 \%$ to $99.0 \%$ and $90.0 \%$ to $99.0 \%$ respectively ${ }^{[12]}$. In this study of 65 cases, benign were found to be more common constituting $66.15 \%$ cases which is in co-ordinance with the study conducted by Hariprasad S et al. ${ }^{[13]}$ of 159 cases, 109 cases $(68.55 \%)$ were non-neoplastic. Once the cytological diagnosis was made, all the patients were subjected to total thyroidectomy. There were 0 complications post operatively. The histological diagnosis were made and then noted. Majority of cases (70.8\%) were benign (non-neoplastic) which comprised of $38.5 \%$ cases of colloid goitre, $27.7 \%$ cases of thyroiditis and $4.6 \%$ of follicular adenoma, which was in accordance to Md. Shafiqul Islam et al. out, seventy one cases out of $90(78.88 \%)$ were found nonmalignant. Correlation of FNAC and histological diagnosis found to be $92.3 \%$ accurate. 60 cases which were diagnosed by cytologically matched its histological diagnosis. Of the other 5 cases 3 were found to be follicular adenoma and 2 were cytologically diagnosed as colloid cyst, which was similar to the finding in the study by Kusum Borsaikia et al. where of 43 cases, 40 cases matched both cytological and histological diagnosis. 
Table 1: Distribution of patients based on the clinical diagnosis

\begin{tabular}{|c|c|c|}
\hline Clinical diagnosis & Number & Percentage (\%) \\
\hline Diffuse goitre & 22 & 33.8 \\
\hline Multi nodular goitre & 19 & 29.2 \\
\hline solitary nodule thyroid & 8 & 12.3 \\
\hline Ca Thyroid & 16 & 24.6 \\
\hline Total & 65 & 100.0 \\
\hline
\end{tabular}

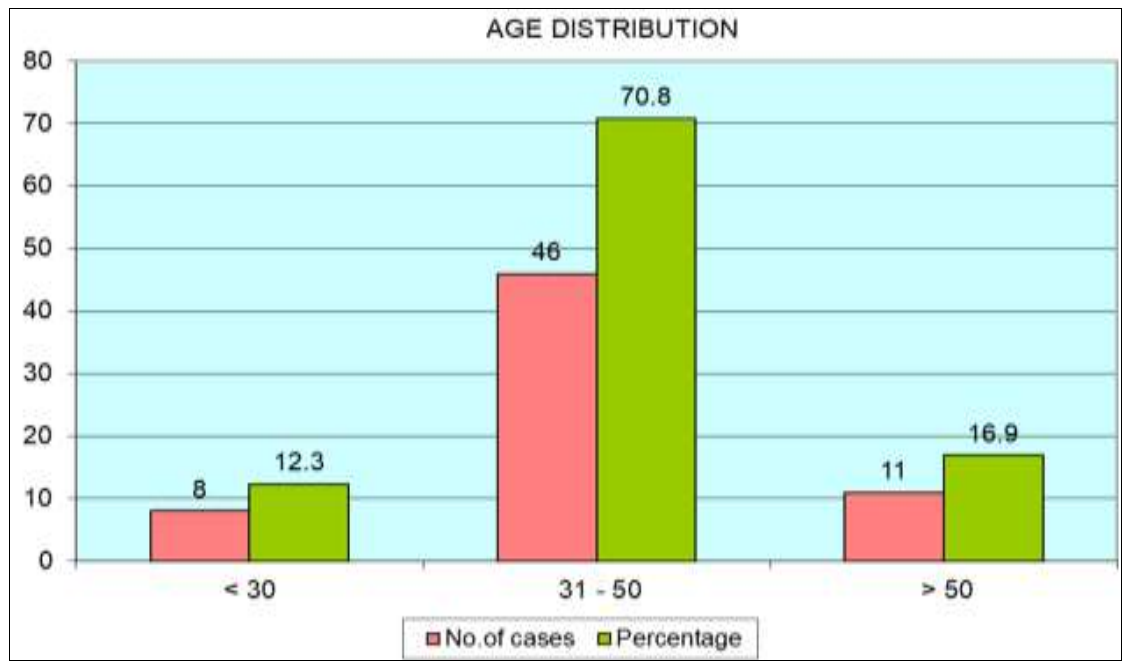

Graph 1: Distribution of patients based on the age

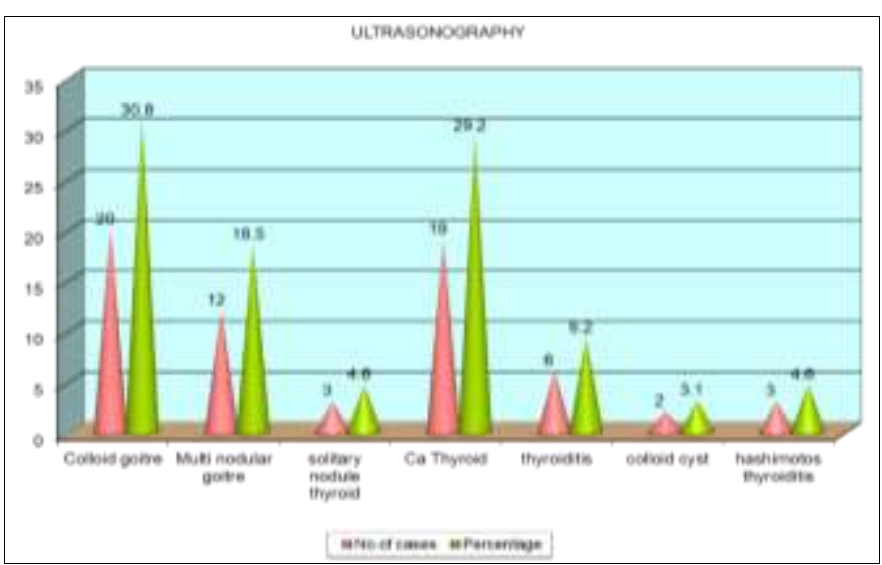

Graph 3: Distribution of patients based on the ultrasonography

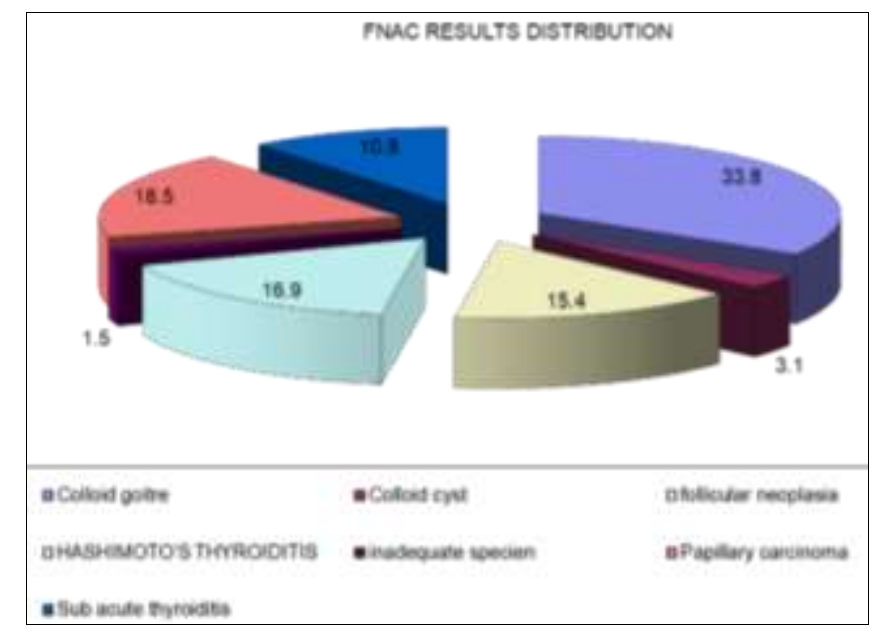

Graph 5: Distribution of patients based on the histological findings

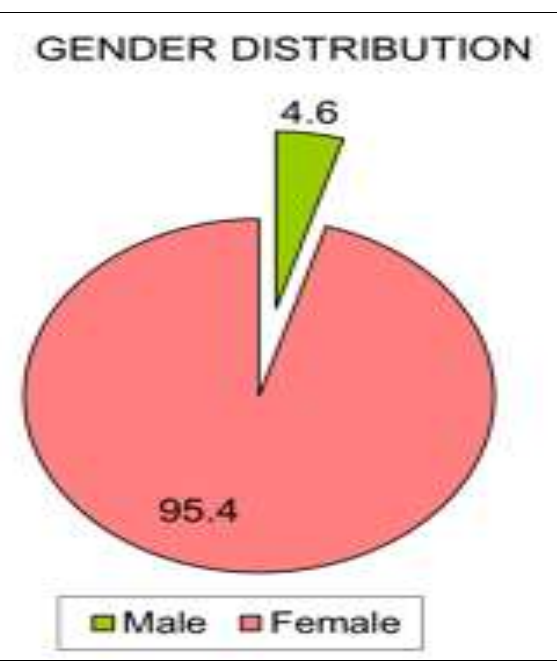

Graph 2: Distribution of patients based on the gender

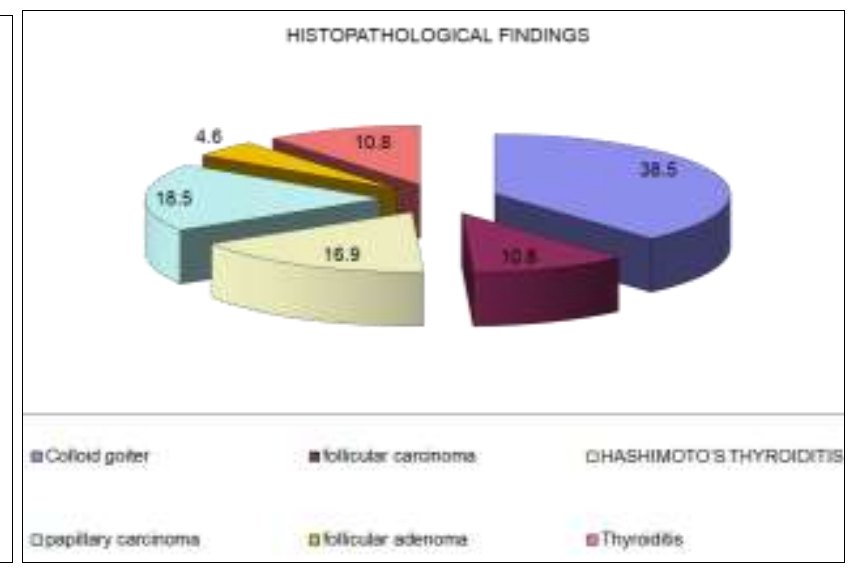

Graph 4: Distribution of patients based on the FNAC results

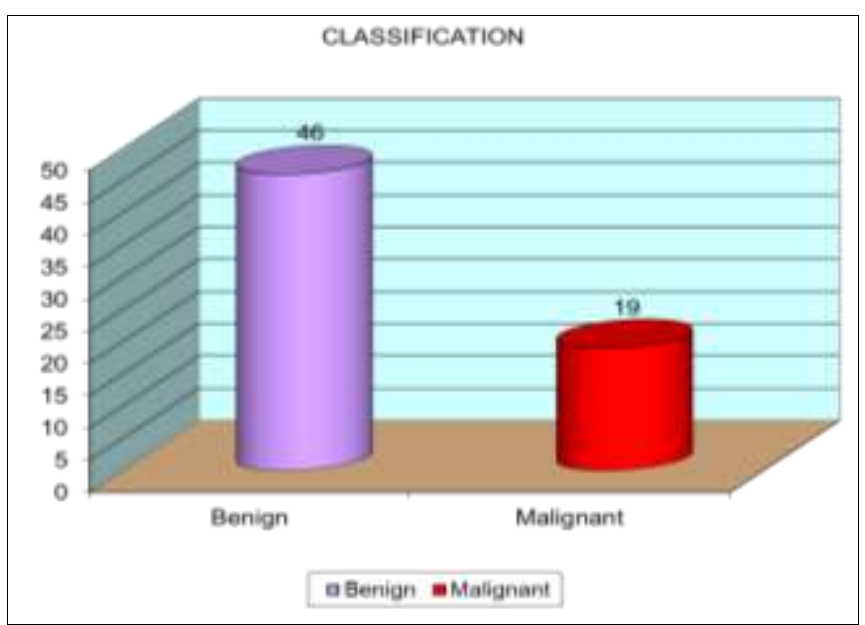

Graph 6: Distribution of patients based on the tumor classification 
Table 2: Distribution of patients based on the histopathological diagnosis

\begin{tabular}{|c|c|c|c|c|c|c|}
\hline & & HISTOPATHO & LLOGICAL DIAC & NOSIS & & \\
\hline $\begin{array}{l}\text { FNAC } \\
\text { DIAGNOSIS }\end{array}$ & COLLOID GOITRE & THYROIDITIS & $\begin{array}{l}\text { FOLLICULAR } \\
\text { ADENOMA }\end{array}$ & \begin{tabular}{|l|} 
FOLLICULAR \\
CARCINOMA
\end{tabular} & \begin{tabular}{|l|} 
PAPILLARY \\
CARCINOMA
\end{tabular} & $\begin{array}{l}\text { MEDULLARY } \\
\text { CARCINOMA }\end{array}$ \\
\hline $\begin{array}{l}\text { COLLOID } \\
\text { GOITRE } \\
\end{array}$ & 22 & & & & & \\
\hline $\begin{array}{l}\text { COLLOID } \\
\text { GOITRE }\end{array}$ & 2 & & & & & \\
\hline THYROIDITIS & & 18 & & & & \\
\hline $\begin{array}{l}\text { FOLLICULAR } \\
\text { NEOPLASM }\end{array}$ & & & 3 & 7 & & \\
\hline $\begin{array}{l}\text { PAPILLARY } \\
\text { CARCINOMA }\end{array}$ & & & & & 12 & \\
\hline $\begin{array}{l}\text { MEDULLARY } \\
\text { CARCINOMA }\end{array}$ & & & & & & \\
\hline INCONCLUSIVE & 1 & & & & & \\
\hline
\end{tabular}

\section{Conclusion}

Thyroid swellings are more predominantly seen in female gender in the age group of 30- 50 years. Most of the swellings are benign in nature, of which colloid goitre is the most common in our study. Fine needle aspiration cytology (FNAC) is a very much reliable as well as economical pre-operative investigation that can use for the evaluation of the thyroid swellings. Surgical management is the definite treatment for thyroid swellings, of which total thyroidectomy is the most preferable type as the rate of recurrences are very low.

\section{Source of funding: Self}

\section{Conflict of interest: Nil}

\section{References}

1. Decker GAG, du Plessis DJ, Lee McGregors. Synopsis of Surgical Anatomy, The Thyroid, thymus, parathyroid gland 198

2. Abu-Eshy SA, Khan AR, Khan GM, al-Humaidi MA, alShehri MY, Malatani TS. Thyroid malignancy in multinodular goitre and in a solitary nodule. J R Coll Surg Edinb 1995;40:310-2.

3. Seymour I, Schwartz F, Charles Brunicardi, Dana K Andersen, Timothy R Billiar, David L Dunn. Schwartz's principles of surgery 2005, 1633

4. Davies L, Welcha HG. Increasing incidence of thy. Ca in the US, 1973-2002,JAMA 2006;295:2164.

5. Maitra A. Thyroid gland. In: Kumar V, Abbas AK, Fausto N, Aster JC, editors Robbin and Cotran Pathological Basis of Disease. 8th Ed. Philadelphia: Saunders Co 2010:11071126.

6. Ridgway EC. Clinical evaluation of solitary thyroid nodules, in The Thyroid: A Fundamental and Clinical Text, G. B. Lippincott, Philadelphia, Pa, USA 1986, 1377-1385

7. Subhash N Halbhavi, Mahantayya Ganjigatti, Shrikant B Kuntoji, Mohammedgouse A Karikazi. Clinicopathological study of thyroid swellings in HSK hospital in Karnataka, India, Int Surg J 2018;5(2):420-425.

8. Kusum Borsaikia, Mukul Patar. Clinicopathological Study of Thyroid Swellings with Some Emphasis on Geographical and Community Distribution: A Hospital Based Analysis, Bengal Journal of Otolaryngology and Head Neck Surgery 2016;24(2):74-79.

9. Ghazaleh N, Haddadinezhad S, Jafari M. Fine needle aspiration cytology of thyroid nodules: correlation with surgical histopathology. Terk Jem 2008;12:73-4.
10. Md. Shafiqul Islam, Belayat Hossain Siddiquee, Nasima Akhtar, Kazi Shameemus Salam, Mohammad Aktaruzzaman. Comparative study of FNAC and histopathology in the diagnosis of thyroid swelling, Bangladesh J Otorhinolaryngol 2010;16(1):35-43.

11. Oertel YC. Fine-needle aspiration and the diagnosis of thyroid cancer, Endocrinology and Metabolism Clinics of North America 1996;25(1):69-91.

12. Raab SS, Vrbin CM, Grzybicki DM, Sudilovsky D, Balassnian R, Zarbo Aspiration. Am J Clin Pathol 2006;(6);125:873-82. 